\title{
La construcción especular del yo a través de la ficción en "Que ma joie demeure" de Michel Tournier
}

\author{
Borja MOZO MARTÍN \\ Universidad Complutense de Madrid \\ Departamento de Filología Francesa \\ borjamozomartin@ucm.es
}

Recibido: 22/02/2013

Aceptado: 11/11/2013

\begin{abstract}
Resumen
La construcción especular de la identidad, omnipresente en el ámbito temático, desempeña un papel fundamental como mecanismo estructural en la obra de Michel Tournier. Tanto es así, que el diálogo permanente entre contrarios, así como la superposición de niveles referenciales que se produce en sus textos, nos obligan a reflexionar sobre la adscripción genérica de los mismos. El presente artículo estudia dicho fenómeno en Que ma joie demeure (1978) publicado unos meses más tarde que Le Vent Paraclet, único texto "autobiográfico" del autor. Tomando como punto de referencia la figura del payaso y la dinámica del espectáculo circense, y basándonos en los conceptos benjaminianos de Erlebnis y Erfahrung, proponemos dos lecturas posibles y complementarias del cuento. Ambas están centradas en el triple procedimiento de inversión, mitificación y apropiación, mediante el cual Tournier pone en duda la unidad constitutiva del individuo y difumina los límites entre (auto)biografía y ficción.
\end{abstract}

Palabras clave: Tournier, circo, identidad, autobiografía, retórica, ficción.

\section{La construction spéculaire du moi à travers la fiction dans "Que ma joie demeure" de Michel Tournier}

\begin{abstract}
Résumé
Omniprésente au niveau thématique, la construction spéculaire de l'identité joue un rôle fondamental en tant que composante structurale de l'œuvre de Michel Tournier. A tel point que le recours permanent au dialogue entre les contraires, ainsi qu'à la superposition de plusieurs niveaux de référence, nous obligent sans arrêt à nous interroger sur le statut générique des textes. Cet article analyse ce phénomène dans "Que ma joie demeure" (1978), publié quelques mois après Le Vent Paraclet, seul texte "autobiographique" de l'auteur. A partir de l'étude de la dynamique du spectacle clownesque, et en nous appuyant sur les concepts benjaminiens d'Erlebnis et Erfahrung, nous proposons deux lectures complémentaires du conte. Elles seront toutes deux centrées sur le triple procédé d'inversion, mythification et appropriation dont se sert Tournier pour mettre en cause l'unité constitutive de l'individu et estomper les limites entre (auto)biographie et fiction.
\end{abstract}

Mots clés : Tournier, cirque, identité, autobiographie, rhétorique, fiction. 


\title{
The Specular Construction of the Self through Fiction in Michel Tournier's "Que ma joie demeure"
}

\begin{abstract}
Thematically omnipresent, the specular construction of identity plays a key role as a structural device in Michel Tournier's works. The permanent dialogue between opposites, together with a multi-layered referential system, constantly obliges us to redefine the generic status of his texts. This paper analyses this issue in "Que ma joie demeure" (1978), published a few months later than Le Vent Paraclet, the only "autobiographical" text by the author. By taking as a reference the clown character and the dynamics of the circus show, and following Walter Benjamin's concepts of Erlebnis and Erfahrung, we propose two possible and complementary readings of the tale. Both of them focus on the triple procedure of inversion, mythification and appropriation, used by Tournier to question the constitutive unit of the individual and to blur the limits between (auto)biography and fiction.
\end{abstract}

Key words: Tournier, circus, identity, autobiography, rhetoric, fiction.

Sumario: Introducción. 1. De la(s) biografia(s) al mito: el cuento como experiencia. 2. De la autobiografía al mito: el cuento como vivencia. 3. La ficción como soporte del yo: el espejo y la máscara.

\section{Referencia normalizada}

Mozo Martín, B. (2014). "La construcción especular del yo a través de la ficción en 'Que ma joie demeure' de Michel Tournier”. Thélème. Revista Complutense de Estudios Franceses, Vol. 29, Núm. 1: 173-198. http://dx.doi.org/10.5209/rev_THEL.2014.v29.41603

\section{Introducción}

Écrivain. Entendu cette définition par un enfant: Ils habitent la campagne et ils sont souvent morts. Autrement dit, en dehors de leurs livres, ils n'existent pas. Ce qui est juste, amer et exaltant.

(Tournier, 1994a: 66)

La aparente ingenuidad de la definición tournieriana de escritor apenas disimula la perspectiva irónica del autor francés sobre su propia condición y, por extensión, sobre su propio yo. Perspectiva tremendamente contradictoria, puesto que, pretendiendo ser subjetiva (propia), se apoya en un primer momento en la mirada de otro sobre uno mismo, y por lo tanto es a la vez ajena. Este proceso de expresión de la identidad gira en torno al concepto de apropiación, sobre el cual Tournier basa lo que podríamos considerar su diccionario personal: Le pied de la lettre. Trois cents mots propres. El título de esta obra ya plantea, mediante un juego de palabras, la problemática relación entre el Yo y el Otro, entre lo propio y lo ajeno, o si se prefiere, entre lo propio y lo común. Al transformar trescientos nombres comunes en "nombres propios", Michel Tournier no hace sino repetir un movimiento bidireccional que vertebra su relación con el mundo y dibuja al mismo tiempo su identidad: dirige su mirada hacia un concepto común, colectivo, ajeno 
("aburrimiento", "imán" o "jungla" por poner algunos ejemplos) y posteriormente lo atrae hacia él, lo inserta en su universo personal.

En el caso de la palabra "escritor", la operación resulta más compleja, debido a que sujeto y objeto se confunden. El movimiento queda anulado ante la ausencia de exterioridad, ante la imposibilidad que tiene el sujeto de contemplarse como objeto. ¿Cómo, entonces, apropiarse de uno mismo? ¿Cómo salir del yo para regresar a él? ¿Cómo decirse? Esa dificultad de hablar de uno mismo de forma directa es la consecuencia de la paradoja que destaca Philippe Lejeune en toda escritura autobiográfica:

passer à l'autobiographie, c'est entrer dans un système de contraintes très astreignant. Par définition, la matière même de mon texte va m'être imposée par la réalité (par la mémoire); et comment échapper à certaines formes de discours et à leurs pesanteurs (la cohésion narcissique de la première personne; les relations explicatives du récit)? La libre activité de l'écrivain est ici ficelée, perpétuellement entravée, l'exigence (immédiatement perçue comme chimérique) de vérité semble devoir s'opposer complètement à l'art. Quadrature du cercle: on ne semble pouvoir devenir autobiographe qu'en renonçant à être écrivain... (Lejeune, 1991: 56-57).

En este caso, Tournier opta por una definición indirecta, obtenida mediante discurso interpuesto. Y no es de ningún modo casual que escoja para ello la voz de un niño, puesto que no sólo siente predilección por el público infantil, sino que en multitud de ocasiones llega a identificarse con él. El autor de Le Roi des aulnes admira la infancia como estado de lo que Freud denominó "narcisismo primario", dicho de otro modo: como "le plein épanouissement d'un être fort de son parfait équilibre" (Tournier, 1978a: 21), estado previo a la degradación que supone la edad adulta, con todos los problemas identitarios que ésta conlleva.

Tanto el contenido de la "cita" del niño como el tono de la definición nos permiten dudar de la existencia del interlocutor de Tournier, sobre todo teniendo en cuenta la tendencia de este último a atribuirse frases o pensamientos de sus personajes en las numerosas entrevistas que concede. Dentro del mecanismo de apropiación, ese supuesto niño cumple dos funciones. Por un lado, actúa como espejo donde el sujeto proyecta su propia imagen en forma de reflejo, para retomarla después y hacerla suya. Pero no olvidemos que el sujeto se presenta frente al espejo bajo una identidad prestada y no a rostro descubierto. Por lo tanto, a la función de espejo habrá que añadir la de máscara. Una máscara que representa una deformación burlona del rostro del autor, ya que ese "Ils habitent la campagne et ils sont souvent morts" no es una alusión genérica a todos los escritores, sino una referencia a la autobiografía del propio Tournier, que efectivamente vive en el campo (concretamente en una casa parroquial rehabilitada en Choisel). La cuestión de la "muerte del autor" cobra doble sentido: no sólo como idée reçue según la cual ya no habría escritores como los de antes, sino sobre todo como alusión a la teoría de Roland Barthes que pone en duda al autor como único responsable del sentido del texto (Barthes, 1984: 61-67). Esta segunda interpretación es reformulada y asumida explícitamente por Tournier en una nueva vuelta de tuerca lúdica y burlesca: "Autrement dit, en dehors de leurs livres, ils n'existent pas." 
Así, esta pequeña definición aparentemente tan ingenua esconde una reflexión existencial y metaliteraria de enorme calado. Michel Tournier plantea la cuestión de la identidad y del vínculo del autor con sus propios textos fingiendo su propia desaparición tras una máscara y un espejo, para reaparecer acto seguido y aceptar el desafío que supone la "muerte": "Ce qui est juste, amer et exaltant". Esta última frase es la única de la definición que surge directamente del escritor, que emerge por fin tras el disfraz y la apropiación, como si su identidad no existiera en sí, como si fuera el fruto de un proceso de construcción que pasa por la confrontación con el otro.

Nuestro estudio analizará la problematización de este proceso de construcción de la identidad en el cuento de Michel Tournier "Que ma joie demeure", incluido en el volumen Le Coq de bruyère (1978), publicado unos meses más tarde que Le Vent Paraclet, único texto "autobiográfico" del autor y muy posiblemente redactado de manera simultánea. Observaremos cómo confluyen en el relato varios niveles referenciales que hacen necesaria una reflexión sobre la adscripción genérica del mismo. Tomando como punto de referencia la figura del payaso y la dinámica del espectáculo circense, y basándonos en los conceptos benjaminianos de Erlebnis y Erfahrung, propondremos dos lecturas posibles y complementarias del cuento. Ambas estarán centradas en el triple procedimiento de inversión, mitificación y apropiación, mediante el cual Tournier pone en duda la unidad constitutiva del individuo y difumina los límites entre autobiografía y ficción. Una vez establecido el vínculo entre estos dos enfoques, ofreceremos una serie de conclusiones sobre el papel de la ficción en la construcción del yo de un autor que no está muerto ni en sentido literal ni en sentido figurado.

Pero antes de adentrarnos en el análisis del texto, cabe señalar el estatus ficcional del mismo, que nos aleja a priori de toda perspectiva autobiográfica. Consideración más que evidente, a juzgar por dos de las informaciones de que disponemos, pertenecientes a lo que Gérard Genette denomina "paratexto" (Genette, 1987): el subtítulo y la dedicatoria. Incluido en un volumen de cuentos, "Que ma joie demeure" lleva por subtítulo "Cuento de navidad" y nada permite identificar en un primer momento al narrador de la historia con el autor de la misma, por lo que el esquema genettiano del "relato factual" $(A=N)$ no se cumple. Nos encontramos claramente ante un "relato ficcional" $(A \neq N)$, concretamente ante una "ficción heterodiegética" (Genette, 2004: 157-158). Además, el autor, cuyo "yo" aparece de forma explícita únicamente en la dedicatoria, establece en la misma un pacto de lectura claramente ficcional, aunque aluda vagamente a la referencialidad de la historia narrada. Se trata, en efecto, de una historia "inventada": "Pour Darry Cowl, cette histoire inventée qui lui en rappellera une vraie" (Tournier, 1978b: 86). Nuestra primera lectura del cuento partirá de estas premisas, que posteriormente matizaremos. 


\section{De la(s) biografía(s) al mito: el cuento como experiencia}

Por otra parte, y con el fin de plantear de forma más clara los dos tipos de lectura que proponemos, identificaremos cada uno de ellos con una versión de la dedicatoria: la traducción al castellano de Lourdes Ortiz y la original. Esta elección viene justificada por el hecho de que la primera no es una traducción literal de la segunda, y la variante ofrecida por la traductora elimina la polisemia de la versión francesa, modificando así la lectura del texto. Lourdes Ortiz sustituye el original "Para Darry Cowl, esta historia inventada que le recordará a una de verdad" por "Para Darry Cowl, esta historia inventada que le recordará una verdad" (Tournier, 1988: 92) ${ }^{1}$. La diferencia no es insignificante, ya que la primera deja abierto el horizonte de expectativas del lector, que puede prever tanto la ficcionalización de un referente "real" como la expresión de una idea a modo de exemplum; mientras que la segunda restringe el cuento a esta última función. Esto, como veremos, no supone una lectura errónea por parte de la traductora, sino simplemente una lectura sesgada. Pero no hay mal que por bien no venga, y la interpretación de Lourdes Ortiz nos ofrece la oportunidad de considerar "Que ma joie demeure" desde un punto de vista clásico, diferenciando esta lectura de otra más moderna, que veremos más adelante.

Denominamos punto de vista "clásico" y "moderno" a las funciones que Walter Benjamin atribuye respectivamente al relato tradicional y a la novela moderna y que relaciona, en su célebre ensayo "El narrador", con los términos de Erfahrung y Erlebnis. Estos conceptos designan dos modos diferentes de concebir la experiencia: el primero se refiere a un consejo práctico, una moral articulada, transmisible, acumulable y compartida por una comunidad (que hemos traducido por experiencia), mientras que el segundo representa el presente de la vivencia, su estado pre-lingüístico e individual, intransmisible (en este caso hemos optado por el término vivencia). Dicho esto, abordaremos de forma bastante esquemática -puesto que no se trata del aspecto central de este trabajo, sino de una base necesaria para las reflexiones que vendrán a continuación- el cuento de Michel Tournier desde el paradigma de la experiencia (Erfahrung).

"Que ma joie demeure" presenta una estructura que podríamos calificar de tradicional, en tanto en cuanto puede leerse como un cuento donde las distintas unidades narrativas se encuentran al servicio de una moraleja, en este caso la necesaria superación de una ruptura mediante la conciliación de los opuestos para la consecución de la felicidad, o lo que es lo mismo, de la perfección. Tema recurrente en los relatos de iniciación y en la obra de Tournier, la contradicción o ruptura de la unidad aparece ya en la pregunta retórica que abre el relato y que nos indica que éste va a estar sometido a una idea. La situación inicial presenta a un niño prodigio

\footnotetext{
${ }^{1}$ En ambos casos, el subrayado es nuestro.
} 
con una carrera exitosa pero sacrificada que consigue alcanzar una primera felicidad mediante el compromiso con una compañera de conservatorio. Esa situación ideal es alterada por un elemento perturbador: el amigo que propone a Raphaël que le sustituya durante su ausencia en la sala de fiestas; momento señalado mediante una construcción arquetípica: "Mais le destin devait éprouver un équilibre aussi précieux" (Tournier, 1978b: 89). A partir de ese instante, el que fuera niño prodigio entra en un proceso de decadencia como artista cómico que culmina con su éxito como payaso en contra de su voluntad. Sin embargo, al final, el arcángel bajo cuya protección lo habían puesto sus padres al nacer acude para evitar su corrupción total. En palabras de Arlette Bouloumié: "Au terme de son voyage, le héros des romans de Michel Tournier atteint donc au plus haut degré de l'initiation. La reconquête de l'androgynat initial exprime la perfection de l'unité retrouvée" (Bouloumié, 1988: 185).

Como las Novelas ejemplares de Cervantes, el cuento está cimentado sobre la figura del oxímoron, que acabará resolviéndose al final de la acción mediante redefinición de los contrarios (operación que se traduce en inversión, y que desemboca, como veremos más adelante, en apropiación). Este razonamiento simplificado en una pareja de conceptos hace del texto literario un silogismo desarrollado y literaturizado, un epiquerema en términos de retórica clásica:

Il est sans doute inutile d'insister sur l'intérêt de l'épichérème: sous cette forme lâche et impure, le syllogisme se retrouve en effet dans tout discours, oratoire ou littéraire. La littérature discursive du classicisme ne laisse pas en effet de raisonner; mais ce raisonnement, tantôt intellectuel tantôt affectif, est littéraire -ce mot est ici presque synonyme de rhétorique, d'ailleurs,- et non pas logique: une proposition n'est pas immédiatement suivie par une autre, mais par un commentaire destiné à l'’illustrer", pour le plaisir de l'esprit et des sens (Kibédi Varga, 1970: 65).

Desde esta perspectiva, podríamos resumir la problemática planteada por el relato de la forma siguiente: Raphaël Bidoche es un gran pianista. No se puede triunfar como pianista si uno se apellida Bidoche. Por lo tanto Raphaël Bidoche no triunfará nunca como pianista. Así, la dinámica de la búsqueda de la felicidad por parte de un personaje predestinado a no conseguirla bajo la influencia de su propio nombre irá desarrollándose en forma de parejas de términos opuestos. Para no extendernos más de lo necesario, comentaremos dos ejemplos que se encuentran respectivamente al principio y al final de "Que ma joie demeure" y que representan el origen de la oposición y su solución. El primero, "grand pianiste international" (Tournier, 1978b: 87), no es en sí un oxímoron, pero la influencia del apellido Bidoche altera el significado de los términos y los vuelve incompatibles entre sí: cuando Raphaël es un gran pianista y tiene un buen futuro por delante, no saldrá nunca de París, por lo tanto no alcanzará la fama internacional; por otro lado, cuando finalmente sea conocido en todo el mundo, no será como gran pianista, sino como payaso. El segundo ejemplo, "celui qui depuis toujours veillait sur lui et le gardait de devenir tout à fait Bidoche" (Tournier, 1978b: 99), con el que se cierra el cuento, es una dilogía o antanaclasis, figura retórica que consiste en la "repetición de significantes idénticos que pertenecen a palabras distintas por sus significados" 
(Albaladejo, 1991: 140): el "lui", que se refiere evidentemente a Raphaël Bidoche, anticipa, aparentemente, la mención final al apellido del protagonista. Sin embargo, la palabra "Bidoche" aparece aquí en su significado literal, es decir "carnaza" en francés (en castellano el efecto se ve reforzado gracias al uso de la palabra Borrego). Es decir, que Raphaël Bidoche alcanzará la felicidad aun llevando su apellido porque ha aprendido a asimilar su identidad doble.

La dinámica de los contrarios aparece reflejada en la obra de Tournier en las múltiples manifestaciones de la figura del doble (niño/adulto, gemelo, andrógino, ogro/ángel) y repercute en todas las instancias narrativas. El personaje de Raphaël se debate entre dos polos opuestos que se irán ampliando a lo largo del relato hacia lugares, objetos y otros personajes, en una oscilación permanente entre lo ascensional y lo descensional, lo áureo y lo grotesco, lo sagrado y lo profano. Por lo tanto, todo en el relato está sujeto a la dialéctica de lo que el autor llama inversión: "cette mystérieuse opération qui sans rien changer apparemment à la nature d'une chose, d'un être, d'un acte retourne sa valeur, met du plus où il y avait du moins, et du moins où il y avait du plus" (Tournier, 1977: 125).

Según este esquema, el piano, con el que el niño prodigio deslumbra a su público, se convierte primero en una herramienta para pagar los gastos del matrimonio gracias a las clases particulares y finalmente en el instrumento desafinado y grotesco del payaso. Del mismo modo, el hogar de Raphaël y Bénédicte, espacio de felicidad del matrimonio, se transforma en una carga económica. Resulta oportuno analizar la disposición de los actantes del relato desde la óptica de la inversión, puesto que ésta no sólo caracteriza su relación con el espacio o los objetos, sino su propia morfología y sintaxis. Observamos que todos los actantes presentan un carácter dual y que a lo largo del relato derivan de un extremo positivo a otro negativo y viceversa. La inversión que afecta a la relación de cada uno de ellos con el espacio en el que se sitúa surge directamente de una inversión producida en el interior del propio sujeto.

Dicha dualidad, así como la convivencia de personajes más o menos realistas con personajes maravillosos, invitan a leer el relato como una superposición de niveles: el que concierne propiamente a la diégesis, a la anecdótica histórica, y el simbólico o mítico, que remite al libro del Génesis. En este correlato bíblico, Raphaël/Adán, colmado de felicidad en su particular paraíso infantil, encuentra remedio a su soledad en la figura de Bénédicte/Eva. Juntos construyen su propio jardín del Edén, hasta que una voz tentadora (en este caso la del amigo) convence a Raphaël a través de Bénédicte para que lleve a cabo un acto que precipitará su caída y destierro hasta la redención final. La instancia temporal reviste el mismo esquema: la temporalidad mítica se superpone al tiempo cronológico a nivel intradiegético (la sonata actúa como rito que devuelve al tiempo del origen en el paraíso y consagra el espacio profano) y extradiegético (fases del correlato bíblico y particularidades genéricas del cuento de navidad, que se repite todos los años para conmemorar el nacimiento de Cristo). Arlette Bouloumié explica la función de la estructura mítica del relato: 
Nourri des mythes qui nous permettent de mieux déchiffrer le monde actuel, complexe et confus, en nous reportant aux origines, le roman mythologique a des structures temporelles et spatiales particulières. Il se déroule à deux niveaux. Son contenu manifeste se développe dans le monde réel, voire contemporain, son contenu latent renvoie au temps mythique de la Genèse qui correspond à un espace vierge, l'espace vivant de la création du monde, quand les règnes $n$ 'étaient pas séparés et que l'on passait indifféremment de l'un à l'autre (Bouloumié, 1988: 185).

El propio Tournier confirma la intención última de la superposición de niveles al destacar que el relato permanece siempre al servicio de la idea: "Il a toujours été hors de question pour moi de verser dans le genre fantastique. J'entends m'en tenir à un réalisme qui ne rejoint le fantastique que par un paroxysme de précision et de rationalisme, par hyperréalisme, hyperrationalisme" (Tournier, 1977: 114).

Llegados a este punto, conviene recordar que el mensaje transmitido por el cuento tiene un destinatario concreto: Darry Cowl nombre artístico del cómico francés André Darrigaud. Si regresamos por un momento a la dedicatoria original, no resulta descabellado pensar que esa "historia de verdad" a la que Tournier se refiere es en realidad la de su amigo, cuyo apellido tiene connotaciones peyorativas en francés (el sufijo -gaud, presente en palabras como nigaud: atontado) y que decidió cambiárselo para su carrera profesional; eso sí, conservando la partícula Darri en forma de nombre de pila y por lo tanto sin renunciar del todo a su identidad. De hecho, tanto en el personaje de ficción como en el cómico real, el nombre artístico consiste en una re-apropiación del apellido, o de parte del mismo.

Sin embargo, esto no deja de ser una hipótesis de lectura, máxime teniendo en cuenta que existen otras dos referencias extradiegéticas a cómicos reales en el interior del texto: Buster Keaton y Grock. Si bien es cierto que se compara a Raphaël convertido en payaso con ambos, un breve análisis microtextual nos va a permitir decantarnos por el segundo. Pongamos en paralelo los fragmentos donde aparece cada uno de ellos:

Derrière lui, modeste et souriante, Bénédicte s'effaçait sous l'avalanche des compliments [...] La presse fut en effet triomphale. On parla d'un nouveau Buster Keaton. On célébra son faciès triste d'anthropoïde hagard, sa gaucherie catastrophique, la façon grotesque dont il jouait du piano (Tournier, 1978b: 95).

\section{Y posteriormente:}

Plus d'une fois les critiques avaient prononcé le nom de Grock à propos de Bidoche, et déclaré $q u$ 'avec lui le légendaire auguste suisse pourrait avoir enfin trouvé son successeur. Bidoche fit en effet ses débuts sur la piste du cirque d'Urbino, la veille de Noël (Tournier, 1978b: 96-97).

En el primer ejemplo, el narrador utiliza el modalizador discursivo "en effet" para confirmar con sus propias palabras el éxito de Raphaël. El discurso narrativizado de la prensa aparece después, y en ningún caso es asumido por el narrador. Por el contrario, en el segundo ejemplo el discurso indirecto de la prensa aparece en primer lugar y el narrador recurre de nuevo al modalizador "en effet", pero esta vez para confirmar, asumir el discurso de los medios. La elección de Grock como posible referencia ("una historia de verdad") para el personaje de 
Raphaël Bidoche y como ejemplo ("una verdad") del mensaje que se quiere transmitir a Darry Cowl parece evidente si nos remitimos al siguiente fragmento de Le vent Paraclet, donde Tournier confirma la influencia que tuvo el payaso suizo en su vida:

Heureusement il y avait Grock que je n'ai jamais vu au cirque, mais dont le comique si particulier m'a profondément impressionné à un âge important. Le grand problème des clowns, c'est qu'ils forment une catégorie d'interprètes pour lesquelles personne n'écrit et qui sont obligés de créer eux-mêmes leur répertoire. Ils n'ont pas le choix, il faut qu'ils s'inscrivent dans la tradition des auteurs-acteurs - celle de Shakespeare et de Molière, celle aussi de Sacha Guitry-ce qui est évidemment beaucoup leur demander. Grock a consacré sa vie à la mise au point d'un numéro qui durait finalement deux heures pleines. Il y a dans l'art du clown des servitudes qui sont les unes positives, les autres négatives. Le grand clown se doit d'user de toutes les ressources traditionnelles de la piste parmi lesquelles au premier chef l'acrobatie et la musique. Il faut également qu'il fasse appel aux techniques du maquillage poussé jusqu'à la monstruosité et aux "effets spéciaux", perruque tournante, larmes jaillissantes, crâne explosant sous le coup de bâton, etc. En revanche, il n'a le droit ni d'être beau, ni d'être tragique, au premier degré au moins. La laideur et le ridicule sont des traits auxquels il ne peut échapper. Quant au triomphe de Grock, il est le résultat d'une évolution qui n'a pas duré plus d'un siècle et demi, mais qui est pleine d'enseignement pour qui voudrait ébaucher une esthétique du spectacle (Tournier, 1977: 35-36).

Nos hemos permitido subrayar algunos aspectos compartidos por Grock y por el personaje de Bidoche, en especial la referencia final al carácter aleccionador del payaso. Resulta pues obvio que la Erfahrung que subyace en el relato pasa por la elaboración de una estética del espectáculo, que es en sí misma una estética de la duplicidad del artista y del personaje interpretado como parte de una pareja complementaria y encarnación de una función: el payaso rojo y el payaso blanco, la risa en primer grado y la risa en segundo grado. Tendríamos, por lo tanto, el siguiente esquema:

\begin{tabular}{|c|c|c|c|}
\hline $\begin{array}{c}\text { NOMBRE } \\
\text { CIVIL }\end{array}$ & $\begin{array}{c}\text { NOMBRE } \\
\text { ARTÍSTICO }\end{array}$ & PAPEL/FUNCIÓN & $\begin{array}{c}\text { MUNDO DE } \\
\text { REFERENCIA }\end{array}$ \\
\hline $\begin{array}{c}\text { André } \\
\text { Darrigaud }\end{array}$ & Darry Cowl & $\begin{array}{c}\text { p.ej: procurador } \\
\text { tartamudo }\end{array}$ & Extradiegético \\
\hline Adrian Wettach & Grock & $\begin{array}{c}\text { Augusto - payaso } \\
\text { rojo }\end{array}$ & $\begin{array}{c}\text { Extradiegético e } \\
\text { intradiegético }\end{array}$ \\
\hline
\end{tabular}




\begin{tabular}{|l|l|c|c|}
\hline & Bidoche & $\begin{array}{c}\text { Augusto - payaso } \\
\text { rojo } \\
\text { Bidoche }\end{array}$ & Intradiegético \\
\hline
\end{tabular}

El mecanismo textual puesto en marcha por Tournier en "Que ma joie demeure" está basado en la superposición de dos referentes extradiegéticos y del personaje inventado mediante el recurso al mito:

Le passage de la métaphysique au roman devait m'être fourni par le mythe. Qu'est-ce qu'un mythe? A cette question immense, je serais tenté de donner une série de réponses dont la première, la plus simple, est celle-ci: le mythe est une histoire fondamentale. Le mythe, c'est tout d'abord un édifice à plusieurs étages qui reproduisent tous le même schéma, mais à des niveaux d'abstraction croissante [...] Un mythe est une histoire que tout le monde connaît déjà (Tournier, 1977: 188189).

El mito entendido como estructura vacía de contenido, como máscara o función que el individuo reactiva al ponerse, puesto que sólo se trata de "recordar" "una verdad" o "una historia de verdad":

André Gide a dit qu'il n'écrivait pas pour être lu mais pour être relu. Il voulait dire par là qu'il entendait être lu au moins deux fois. J'écris moi aussi pour être relu, mais, moins exigeant que Gide, je ne demande qu'une seule lecture. Mes livres doivent être reconnus -relus- dès la première lecture (Tournier, 1977: 189).

En definitiva, y tal como anunciábamos en la introducción de este estudio, el mito como etapa central del proceso de construcción de la identidad del individuo, bisagra entre la inversión y la apropiación, entre la ruptura y la aceptación de la duplicidad, entre lo propio y lo ajeno, lo uno y lo diverso.

\section{De la autobiografía al mito: el cuento como vivencia}

Hemos visto con anterioridad que el cuento responde al esquema triangular de la ficción heterodiegética tal como lo plantea Genette: $A \neq N \neq P[\neq A]$. Sin embargo, la extrema influencia que ejerce la dedicatoria sobre la lectura del texto y la presencia explícita del autor en la misma nos obligan a replantearnos dicha relación analizando detenidamente el estatus del narrador, pieza central del esquema genettiano.

La pregunta inicial otorga al narrador heterodiegético un poder total sobre lo narrado, puesto que en ella establece la dinámica del relato, es decir los términos que entrarán en conflicto. Pero dicha pregunta no implica directamente la asunción de la responsabilidad enunciativa por parte del narrador, teniendo en cuenta que si bien es el encargado de pronunciarla, ésta se sitúa en un "espace de véridiction" (Adam, 1990: 61) externo al relato y al propio narrador. El "on" aleja el contenido de la pregunta no sólo de la autoridad del narrador, sino también del autor, al transmitir una verdad universal que pertenece al ámbito del discurso en presente 
gnómico o atemporal. Este tipo de discurso actualizable consiste, según JeanMichel Adam, en: "présentifier ce qui est disponible (présentifiable potentiellement)" (Adam, 2005: 201), característica acorde con la función transmisora de "una verdad" que cumple el cuento, y propia del mito. La transición entre ese espacio o universo exterior al relato y la propia diégesis relatada por el narrador aparece subrayada por la fórmula "En prénommant [...] relever le défi" (Tournier, 1978b: 87).

En el interior del relato, la presencia de la voz narrativa se hace patente mediante comentarios totalmente subjetivos que subrayan una distancia analítica con respecto a lo narrado. Además, el narrador establece juicios interpretativos sobre los personajes: "expression d'ahurissement buté plus propre à exciter le rire qu'à inspirer le rêve" (Tournier, 1978b: 88), "comme un naufragé à un rocher" (Tournier, 1978b: 95); y sobre el comportamiento de éstos, como por ejemplo el ya citado "En prénommant leur fils Raphaël, en le plaçant sous la protection tutélaire de l'archange le plus aérien et le plus mélodieux, les époux Bidoche commençaient peut-être à relever inconsciemment le défi" (Tournier, 1978b: 87). Esta observación es tanto más propia del narrador por cuanto él mismo reconoce que no procede de los propios padres de Bidoche al incluir "peut-être" y "inconsciemment". Es decir, que el modalizador "peut-être", que puede parecer una renuncia a su omnisciencia si se lo interpreta como una incapacidad de acceder a la interioridad de un personaje, cumple en efecto la función opuesta: la de reforzar el poder del narrador sobre el texto, que está salpicado por su subjetividad. El mismo procedimiento se repite unas páginas más allá, cuando especula sobre los pensamientos de Bénédicte: "Peut-être pensait-elle aussi à son bel appartement résidentiel désormais à sa portée" (Tournier, 1978b: 95). También establece hipótesis o preguntas: "On aurait dit que la mauvaise fée Puberté" (Tournier, 1978b: 88), "Le numéro du piano diabolique était-il tout à fait au point?" (Tournier, 1978b: 98).

Esa fuerte presencia del narrador en el relato se manifiesta en su dominio de las causas y consecuencias de las acciones, de las prolepsis y las analepsis. Precisamente mediante dos prolepsis construye el cronotopo infernal, tanto en su primera fase, cuando aparece Henri y propone a su amigo que le sustituya: "Mais le destin devait éprouver un équilibre aussi précieux" (Tournier, 1978b: 89); como en la segunda, cuando Raphaël cree haber escapado de su trabajo temporal como cómico de sala de fiestas pero en realidad está a punto de hundirse todavía más: "La situation se serait à coup sûr envenimée si le retour de Durieu n'y avait mis fin" (Tournier, 1978b: 92).

El narrador focaliza gran parte del relato en Raphaël Bidoche, puesto que además de acercarnos a su interioridad nos ofrece su punto de vista en determinados episodios. Esto es perceptible gracias al vocabulario modalizador y altamente subjetivo: "l'enfant payait chèrement" (Tournier, 1978b: 87), "impitoyablement enchaîné" (Tournier, 1978b: 88), "Raphaël, ivre d'exaltation et de gratitude" (Tournier, 1978b: 89), "Raphaël évalua la qualité de ce rire [...] reconnut, dans les rafales qui battaient les murs de la petite salle, le rire même du Diable" (Tournier, 1978b: 90), "quelle ne fut pas sa surprise, un soir qu'il se rendait à son enfer 
quotidien" (Tournier, 1978b: 91), "maudissant intérieurement sa timidité" (Tournier, 1978b: 92), "il comprit quel terrible piège [...] tout vibrant et houleux [...] grotesque $[\ldots]$ tout paraissait calculé à dessein pour $[\ldots]$ hurlements de rire $[\ldots]$ longues minutes" (Tournier, 1978b: 94). Cabe destacar que la contemplación del arcángel, que se produce en dos ocasiones, viene condicionada primero por la focalización en el público de la "soirée mondaine": "semblait-il" (Tournier, 1978b: 87); y en la última escena por el punto de vista del protagonista despojado de sus gafas: "Alors dans les nuées moirées de sa myopie, le clown musicien vit" (Tournier, 1978b: 98). Más adelante veremos cómo la problemática de la mirada constituye el eje central del relato.

Pero el procedimiento que más profundamente permite acceder a la interioridad de Raphaël es el discurso indirecto libre, que recoge los pensamientos del protagonista: "Il lui aurait été pénible de s'asseoir [...] cette épreuve sacrilège" (Tournier, 1978b: 89-90), "Et c'était ce déballage ignoble [...] dont il se faisait le complice actif" (Tournier, 1978b: 91), "Jamais il ne redescendrait [...] mais il n'y avait plus rien à y apprendre" (Tournier, 1978b: 93), "Que joua-t-il ce soir-là?" (Tournier, 1978b: 95), "Si des milliers de bourreaux l'abrutissaient de leurs rires bestiaux, du moins avait-il l'avantage de ne pas les voir" (Tournier, 1978b: 98).

La focalización en Raphaël no es exclusiva, puesto que a lo largo del relato el narrador se acerca a otros puntos de vista, aunque veremos que de forma distinta. En primer lugar, destacaremos que el narrador asume hasta en tres ocasiones el punto de vista del público: mediante el ya señalado "semblait-il", posteriormente en la primera parte de la descripción de Bodruche: "Le chansonnier qu'il s'agissait [...] hurlements joyeux de la foule" (Tournier, 1978b: 90), y por último en la descripción de Bidoche: "Coiffé d'un crâne en carton rouge [...] sous sa propre bouffonerie" (Tournier, 1978b: 97). Esta última descripción resulta especialmente significativa, puesto que contrasta con la que se nos ofrece de su primera actuación, realizada desde el punto de vista del propio Raphaël. En este segmento se emplea un punto de vista externo al personaje que actúa, el mismo con el que se había descrito a Bodruche. Así, se aproxima a Raphaël de Bodruche, subrayando su decadencia y objetivándolo.

En el caso de Bénédicte, el narrador accede a su interioridad pero de forma limitada, puesto que sólo se sabe lo que piensa cuando lo expresa directamente a través de palabras, en los segmentos reflexivos (intercambios dialécticos) que anteceden a cada nueva degradación de Raphaël: "Bénédicte lui demanda de réfléchir. Ils étaient fiancés depuis [...] mais bien abstraite de son art?" (Tournier, 1978b: 90), "elle le félicita de son succès [...] Après tout, l'opération n'avait d'autre raison [...] le maximum?" (Tournier, 1978b: 92), "Ce qu'on lui proposait n'avait rien de commun [...] Avait-il le choix?" (Tournier, 1978b: 93-94). El lector desconoce los pensamientos de Bénédicte y debe conformarse con las hipótesis que sobre ello ofrece el narrador: "Bénédicte Prieur semblait insensible [...] elle ne voyait sans doute en lui que" (Tournier, 1978b: 88), "Peut-être pensait-elle aussi" (Tournier, 1978b: 95). Curiosamente, el único momento en que accedemos a sus pensamientos (y no palabras) nos descubre su ambición económica: "Elle rêvait 
d'un appartement ancien et plus spacieux dans un quartier résidentiel" (Tournier, 1978b: 94). Esto dice mucho sobre la visión que el narrador nos da de Bénédicte (ser dual, como ya hemos visto, pero negativizado como Eva corruptora). De hecho, la única descripción física que se hace de ella aparece prácticamente al final del relato, cuando va disfrazada, es decir, cuando su apariencia es totalmente grotesca: "En étroit gilet brodé et culottes [...] faire-valoir du célèbre clown musicien Bidoche" (Tournier, 1978b: 97).

Tampoco tenemos acceso a los pensamientos de los padres, salvo cuando éstos los expresan abiertamente: "et les parents des deux enfants se demandaient avec émerveillement si leurs relations dépasseraient jamais l'intimité extatique" (Tournier, 1978b: 88). Ocurre lo mismo con el director de la sala de fiestas, de quien sólo conocemos las palabras a través del discurso directo o indirecto libre: "Oui, il avait cru devoir porter son nom sur l'affiche [...] Substantiellement" (Tournier, 1978b: 91). Cabe destacar que en un momento dado, las palabras del director y de Bénédicte se funden en un mismo discurso indirecto libre, puesto que la mujer retoma la propuesta del empresario para transmitírsela a su marido: "Non, il ne s'agissait plus d'accompagner le tour de chant [...] d'entrain et de joyeux éclats" (Tournier, 1978b: 93). A su vez, tanto los pensamientos de Henri -"Pourtant, il n'avait pas à se plaindre [...] de prostituer son art" (Tournier, 1978b: 96)- como las opiniones de la prensa - "On célébra son faciès [...] dont il jouait du piano" (Tournier, 1978b: 95)- sólo nos llegan a través del discurso indirecto cuando son expresados públicamente.

El tratamiento de la figura de Bodruche también es digno de mención en este sentido. Personaje totalmente abyecto, su interioridad permanece inaccesible. Se lo describe en primera instancia desde el punto de vista del narrador, que asume el punto de vista del público y lo juzga: "il était affligé d'un physique à l'image de son nom" (Tournier, 1978b: 90). A continuación, se hace lo mismo desde el punto de vista de Bidoche, que ve en él a un personaje grotesco y diabólico: "Raphaël évalua la qualité de ce rire [...] la lâcheté, la bêtise" (Tournier, 1978b: 90-91). Por un momento tenemos la sensación de acceder a sus pensamientos con respecto a Bidoche, pero igualmente podría tratarse de un análisis objetivo de la situación por parte del narrador: "Il l'avait traité jusque là [...] le directeur n'avait pas pu ne pas s'en apercevoir"' (Tournier, 1978b: 92).

Hemos observado que el mismo procedimiento (discurso indirecto libre) se aplica, según el personaje del que se trate, a palabras o pensamientos. El hecho de que sólo conozcamos de forma directa los pensamientos de Bidoche (y algunos fragmentos de los de Bénédicte) y del resto sólo las palabras expresadas constituye una de las características principales del espacio infernal que se desarrolla tras la caída: el poder de destrucción que ejerce sobre el protagonista, cuyos pensamientos quedan asfixiados en cada intercambio dialéctico por las palabras de los demás, que lo conducen a la decadencia. Evidentemente, las particularidades de la focalización están en consonancia con la imagen que el autor nos quiere transmitir de cada uno de los personajes, situándolos en un extremo u otro de su dualidad intrínseca. Accediendo a la interioridad de Bidoche, el narrador nos acerca a su sufrimiento 
previo y posterior a su decadencia, a su percepción subjetiva del espacio infernal y a la conciencia que tiene de su caída y de su propia dualidad. Esto tiene que ver con el hecho de que sea él precisamente quien busque la felicidad: su interioridad así desvelada nos permite observar cómo la alcanza y se aleja de ella alternativamente.

Resulta de especial relevancia, a la hora de analizar el estatus del narrador en el relato, el punto de interacción entre el universo extradiegético y el intradiegético que hemos comentado en el epígrafe anterior: la mención a Grock. Recordemos: "Plus d'une fois les critiques avaient prononcé le nom de Grock à propos de Bidoche, et déclaré qu'avec lui le légendaire auguste suisse pourrait avoir enfin trouvé son successeur. Bidoche fit en effet ses débuts sur la piste du cirque d'Urbino, la veille de Noël" (Tournier, 1978b: 96-97). En este fragmento, al igual que en la pregunta inicial, el estatus del narrador resulta problemático. Asistimos una vez más a un fenómeno de reactualización de una opinión ajena que subraya, como ya anunciaba la dedicatoria del cuento, una interacción entre lo que Tomás Albaladejo llama "modelos de mundo":

El modelo de mundo es el conjunto de instrucciones de índole semántico-extensional que sigue el productor del texto en la obtención de la estructura de conjunto referencial, que se ajusta así a unas condiciones fijadas con anterioridad por el productor al adoptar un modelo de mundo, las cuales determinan el carácter verdadero, ficcional verosímil o ficcional inverosímil de los elementos referenciales (Albaladejo, 1991: 70).

La referencia a Grock pone de manifiesto una distancia entre el narrador y lo expresado que recuerda al mecanismo puesto en marcha por Tournier en su definición de "Escritor": movimiento de desvinculación con respecto a un determinado discurso y posterior apropiación del mismo. Aunque la entidad mediadora no sea en este caso una pura invención del yo que acaba apropiándose el discurso -como el "niño"-, el contenido del enunciado sí tiene un origen ficticio. Que los críticos comparen a Bidoche con Grock es únicamente posible en el mundo ficcional inverosímil de la diégesis que el narrador toma como punto de referencia, puesto que fuera del mismo Grock existe y Bidoche no. El narrador, que había recurrido a un "espace de véridiction" exterior a la diégesis en la pregunta retórica que abre el relato, no inventa nada, sino que fundamenta su opinión en la reactualización de un discurso intradiegético sobre el payaso Grock.

No hay que olvidar que la dedicatoria de "Que ma joie demeure" establece de forma explícita la frontera entre mundos ficcionales, que equivale en este caso concreto a la frontera entre el autor y el narrador. Sin embargo, la alusión al payaso suizo en el cuento responde al mismo esquema estructural que las apariciones de Grock en los textos no-ficcionales de Michel Tournier. Dichas apariciones ponen de manifiesto la considerable distancia entre el sujeto observador-narrador (el propio Tournier) y el objeto observado de forma indirecta (por discurso interpuesto) puesto que el autor francés nunca vio a Grock. En el fragmento de Le vent Paraclet analizado en el epígrafe anterior veíamos surgir al payaso suizo como una ausencia, un factor determinante en la vida del escritor que sin embargo no forma parte de su experiencia vital: "Heureusement il y avait Grock que je n'ai jamais vu au cirque, 
mais dont le comique si particulier m'a profondément impressionné à un âge important" (Tournier, 1977: 35-36). Al no haber visto a Grock, la experiencia proviene necesariamente del discurso de otro, de lo escuchado o leído. De este modo, el payaso pasa a formar parte de la vida de Tournier no como individuo, sino por su "particular comicidad", es decir por lo que representa (una idea, una función dentro de una estructura).

Si la voz narrativa de "Que ma joie demeure" no duda en asumir discursos ajenos, provenientes tanto de un espacio extradiegético (presente gnómico), como intradiegético (palabras o pensamientos de los personajes) o mixto (discurso de la prensa sobre Grock), lo mismo ocurre con el yo auctorial presente en Le vent Paraclet. Ese carácter polifónico es uno de los factores que llevan a Fui Lee Luk a afirmar, en su interesante estudio sobre la subversión de la escritura del yo en Michel Tournier, que el único libro aparentemente autobiográfico del autor es en realidad un "ouvrage autobiographique sans être une autobiographie" (Luk, 2003: 16). Según Luk, dicha obra, que sólo subraya un aspecto de la vida de Tournier -su relación con la creación literaria como soporte de sus aspiraciones filosóficas (Luk 2003, 21)- difícilmente puede responder a la definición canónica de autobiografía que ofrece Philippe Lejeune:

Si nous confrontons Le vent Paraclet à cette définition, certains critères sont satisfaits. Cet ouvrage où Tournier retrace quelques étapes de sa vie est indiscutablement un "récit rétrospectif en prose qu'une personne réelle fait de sa propre existence". Cependant, la deuxième partie de la définition est plus problématique: nous perdons de vue la "vie individuelle" de Tournier et, de plus, son but n'est pas d'expliquer "l'histoire de sa personnalité" (Luk, 2003: 15).

En su "autobiografía intelectual", Tournier no sólo habla de otros autores, sino que comenta su propia obra desde la distancia analítica, como si fuera el crítico de sí mismo. Distancia con respecto a su obra que se convierte en distancia sobre los episodios de su vida personal, apenas esbozados, aludidos y rápidamente olvidados en pos de la reflexión sobre aspectos generales de la historia, la filosofía, la psicología o la literatura. Resulta evidente que en Le vent Paraclet el pensamiento ocupa un lugar privilegiado en detrimento de la personalidad. Nos encontramos sin duda ante una obra paradójica, que "malgré ses lacunes [...] laisse entrevoir certains aspects de la personnalité de Tournier, notamment, sa relation d'amour/haine avec sa condition d'écrivain qui le singularise puisqu'il veut à la fois être connu par ses lecteurs et n'être connu de personne" (Luk, 2003: 28).

La asunción de ese modo de apropiación indirecto de una idea mediante el paso de lo particular a lo general que veíamos surgir en "Que ma joie demeure" constituye en sí una referencia implícita a la formación filosófica del autor, y en concreto a su afinidad por la obra de Jean-Paul Sartre. No debe extrañarnos dicho paralelismo si atendemos al lugar privilegiado que ocupa el concepto mismo de apropiación en el aparato teórico sartriano, y mucho menos si observamos, como hace de forma encomiable Serge Doubrovsky, la importancia de dicho concepto en la configuración del extensísimo espacio autobiográfico del autor de L'Etre et le Néant. Así, afirma Doubrovsky, la apropiación 
renvoie au sujet autobiographique le geste même par lequel, ressaisissant en une totalisation cohérente le sens d'une vie, il la reprend et la récupère. Geste que redouble, à un niveau abstrait, celui du sujet théorique qui, à son tour, fondant en vérité, en raison démonstrative, l'histoire d'un Moi singulier, l'assimile et le digère dans le système. Pour l'écrivain intimiste, par le biais de la notation ou de l'examen, comme pour le penseur universel, au moyen d'une instrumentalité conceptuelle, comprendre, c'est toujours s'approprier (Doubrovsky, 1988: 128-129).

En la obra de Tournier, este mecanismo aparece asimismo reflejado $-\mathrm{y}$ nunca mejor dicho- en Le miroir des idées, tratado compuesto por ciento catorce parejas entre cuyos elementos el autor establece una relación dialéctica. Las partes de cada una de las parejas funcionan no como polos contrarios, sino complementarios, de tal modo que el uno se define únicamente mediante la confrontación con el otro. Como señala Luk, esta obra reviste un carácter doble. Por una parte como testimonio de una subjetividad, puesto que no se trata de conceptos clave pertenecientes a una clasificación reconocida universalmente, sino al universo personal del autor, que los coloca frente al espejo del yo. Por otra, como deseo de mantener una distancia con respecto a los conceptos contemplados, sin emitir juicios de valor sobre los mismos:

Au lieu de se prononcer pour ou contre l'une ou l'autre moitié d'un couple, [Tournier] entreprend de maintenir la neutralité qui lui permet d'apprécier les qualités de chacun. Rejetant tout monisme, il s'ouvre à la possibilité de vivre dans un monde où il existe des nuances qui restent à être éclaircies, des considérations peu familières qui exigent d'être explorées. Avant tout, par cette vision dualiste qui divise le monde en deux pôles également valables, l'écrivain préserve un sens de dynamisme: rien n'est stable, car la vérité se trouve dans le va-et-vient continuel entre les deux extrêmes (Luk, 2003: 92).

Al incluir a Grock en ese mecanismo dual, Tournier no sólo extrapola lo general en lo particular, sino que convierte al individuo en concepto y función dentro de una estructura actualizable similar al mito. Observemos cómo se lleva a cabo el proceso en varias etapas: origen, explicación, encarnación, análisis del contenido simbólico de la estructura descrita y, por último, actualización:

Au début, le clown blanc était seul sur la piste du petit cirque campagnard. Habillé de soie, poudré à frimas, un sourcil relevé très haut sur son front pour exprimer son étonnement hautain, chaussé de fins escarpins vernis, les mollets cambrés dans des bas blancs, ce seigneur éblouissait les paysans venus rire et s'émerveiller. C'était parmi eux qu'il trouvait une tête de Turc. Il choisissait le plus ahuri, le plus rougeaud, le plus balourd. Il le faisait entrer sur la piste illuminée, et bientôt les gradins croulaient de rire à ses dépens.

C'est ainsi qu'est né l'Auguste. Car il apparut bientôt qu'il valait mieux qu'un compère se mêlât au public et vînt donner au clown blanc une réplique préparée à l'avance. Le clown rouge est tout l'inverse du clown blanc. Sa trogne poivrote et son nez chaussé d'une balle de celluloïd cramoisie, ses yeux ahuris, son immense bouche, sa démarche embarrassée par d'énormes croquenots, tout est fait chez lui pour attirer les coups et les lazzis.

Mais le clown rouge a eu sa revanche. Peu à peu il a tiré à lui tout le succès du numéro. Il apparut bientôt que c'était lui la vedette et que le blanc était ravalé au rôle de faire-valoir. Jusqu'à ce que le plus grand Auguste de toute l'histoire du cirque, le Suisse Grock, ayant passé sa vie à perfectionner son numéro, en arrivât à le présenter seul, deux heures durant, sans aucun partenaire.

Il reste que ces deux clowns incarnent deux esthétiques tout opposées du rire. Le blanc cultive l'insolence, le persiflage, l'ironie, le propos à double sens. C'est un maître du second degré. Il fait 
rire des autres, d'un autre, l'Auguste. Mais lui garde ses distances, il reste intact, hors d'atteinte, le rire qu'il déchaîne ne l'éclabousse pas, c'est une douche destinée au rouge qui est là pour encaisser.

Ce rouge s'offre à tous les coups en poussant son discours, son accoutrement et sa mimique au comble du grotesque. Il n'a pas le droit d'être beau, spirituel, ni même pitoyable, cela nuirait à la sorte de rire qu'il a pour fonction de soulever. Rien n'est trop distingué pour le blanc: plumes et duvets, dentelles et taffetas, strass et paillettes. Rien n'est assez burlesque pour le rouge: perruque tournante, crâne de carton sonore, plastron géant et manchettes de celluloïd.

Aussi bien ces deux personnages se retrouvent-ils dans la vie en des proportions certes valables, souvent infimes, mais cependant visibles. Les uns se frappent la poitrine et prennent la foule à témoin de leur sincérité et de leur malheur. Ils se désignent à l'admiration, à la pitié, voire au mépris de la société. C'est le parti pris rouge d'un Rousseau, d'un Napoléon, d'un Mussolini. Au contraire le parti pris blanc d'un Voltaire ou d'un Talleyrand fait les témoins sarcastiques de leur temps, les fins diplomates, les calculateurs, tous ceux qui préfèrent observer et manœuvrer sans s'exposer, gagner sans mettre en jeu leur liberté, leurs biens ni leur personne (Tournier, 1994b: 68$70)^{2}$.

Grock se apropia de la función del Augusto y la actualiza con su propia identidad. Y justamente es esa función, categoría tan vacía como el disfraz y la máscara del payaso, la que da lugar a la confluencia del modelo referencial y del personaje inventado (Raphaël Bidoche) en "Que ma joie demeure". Utilizando la máscara del narrador, que a su vez reúne varios discursos ajenos, Michel Tournier hace de Bidoche el espejo que le permitirá apropiarse del payaso suizo y que, al mismo tiempo, nos muestra la imagen de su propia ausencia. La fórmula de apropiación de la figura ausente de su biografía consistirá en primer lugar en convertir al payaso en estructura actualizable, en mito personal, para posteriormente cubrirse el rostro y adoptar la perspectiva de un yo ficcional. Mediante este gesto, el autor inscribe su obra en una tendencia propia de la modernidad literaria y artística que consiste, según el análisis de Jean Starobinski, en identificarse con las figuras circenses, caracterizadas precisamente por su ausencia de significación y, por ende, por su capacidad para poner en duda las estructuras en las que se basan el individuo y la sociedad:

Mais il faut se garder d'une pareille surcharge allégorique: ce serait assigner au clown, aux saltimbanques, au monde du cirque une signification définie, une fonction stable. Or, pour qu'ils puissent vivre, ils doivent d'abord jouir d'une liberté plénière. [...] La gratuité, l'absence de signification est, si je puis dire, leur air natal. C'est seulement au prix de cette vacance, de ce vide premier qu'ils peuvent passer à la signification que nous leurs avons découverte. Ils ont besoin d'une énorme réserve de non-sens pour pouvoir passer au sens. [...] Le non-sens dont le clown est porteur prend alors, en un second temps, valeur de mise en question; c'est un défi porté au sérieux de nos certitudes (Starobinski, 2013: 112).

Sin atrevernos a afirmar rotundamente la identidad entre autor y narrador en "Que ma joie demeure", los paralelismos con los textos no-ficcionales de Tournier

\footnotetext{
${ }^{2}$ Nos hemos permitido subrayar en el texto las articulaciones del discurso que marcan el paso de una etapa a otra.
} 
justifican, al menos, la posibilidad de una cierta similitud entre ambas instancias, que constituiría una marca estructural de la presencia auctorial en el texto de ficción. Esto nos llevaría a introducir una ligera modificación en el esquema de Genette: $\mathrm{A}(\neq) \mathrm{N} \neq \mathrm{P}[\neq \mathrm{A}]$.

"Que ma joie demeure", relato de la búsqueda del otro y de la definición del yo, se sitúa por tanto en un punto de contacto entre Erfahrung (experiencia articulada y transmisible) y Erlebnis (vivencia individual), como una tensión entre ambos paradigmas:

Celui qui écoute une histoire se trouve en compagnie du conteur; même celui qui la lit partage cette compagnie. Le lecteur du roman, lui, est solitaire. Il l'est plus que tout autre lecteur. (Car même celui qui lit un poème est enclin à lui prêter sa voix pour un auditeur éventuel.) Dans cette solitude, le lecteur de roman s'empare plus jalousement que personne de la matière qui lui est offerte. Il est prêt à se l'approprier tout entière et en quelque sorte à l'engloutir. Il est, à l'égard de cette matière, comme le feu qui dévore et anéantit les bûches dans la cheminée. La tension qui traverse le roman ressemble fort à l'appel d'air qui avive la flamme et la fait jouer dans l'âtre [...] L'importance, dans le roman, ce n'est donc pas qu'il nous instruit en nous présentant un destin étranger, mais que ce destin étranger, par la flamme qui le consume, nous procure une chaleur que nous ne trouverions jamais dans notre propre vie (Benjamin, 2000: 138-139).

\section{La ficción como soporte del yo: el espejo y la máscara}

Dado que un estudio completo de la construcción del yo tournieriano sobrepasaría el contexto del presente trabajo, nos limitaremos a ofrecer en esta última parte una serie de conclusiones relativas al funcionamiento del mecanismo de la construcción de la identidad en el relato, así como a la manifestación del tema de la duplicidad del yo en los motivos de la mirada, el espejo y la máscara. Para ello, nos centraremos en la caracterización del personaje de Raphaël Bidoche, en su triple vertiente de niño, payaso y artista.

No es casual que la resolución de la problemática duplicidad del ser se produzca con Raphaël Bidoche disfrazado de payaso. Como señala C.G. Jung en un artículo dedicado a la figura del trickster, definido como "a psychologem, an archetypal psychic structure of extreme antiquity" (Jung, 1972: 200) que representa la dualidad y asociado posteriormente con el payaso, no será hasta la asunción de la sombra (the shadow, parte de la psique enterrada por el subconsciente) cuando el individuo vuelva a ser una unidad:

Only when his consciousness reached a higher level could he detach the earlier state from himself and objectify it, that is, say anything about it. [...] It was possible only when the attainment of a newer and higher level of consciousness enabled him to look back on a lower and inferior state (Jung, 1972: 202).

${ }^{3}$ Recordemos que en la dialéctica benjaminiana la "histoire" es el soporte de la experiencia (Erfahrung), mientras que el "roman" está relacionado con la vivencia (Erlebnis). 


\section{De ahí que:}

The conflict between the two dimensions of consciousness is simply an expression of the polaristic structure of the psyche, which like any other energic system is dependent on the tension of opposites. [...] The unity of the psyche's nature lies in the middle, just as the living unity of the waterfall appears in the dynamic connection of above and below (Jung, 1972: 209).

Para que esa recuperación de la parte del yo enterrada en el subconsciente se lleve a cabo, es necesario situarse al nivel de una consciencia superior, es decir exterior o posterior al individuo. En el caso del payaso, esa consciencia superior está representada por el público, que ve en el personaje rasgos que identifica como pertenecientes a sí mismo en un estado animal, torpe, corpóreo, es decir ya superado gracias a la civilización. Al interpretar al payaso en la escena final y provocar deliberadamente la comicidad, Raphaël abandona el lugar de objeto observado para desdoblarse en sujeto observador, adquiriendo esa consciencia superior que le permite objetivarse y verse como un todo: así, ya no estaremos hablando de Raphaël/Bidoche, sino de Raphaël+Bidoche. La perspectiva del personaje supone una distancia con respecto a sí mismo que abarque al mismo tiempo y desde fuera su mirada y la del público. La frase de su amigo Henri Durieu adquiere un nuevo significado: "Chacun doit obéir à sa vocation" (Tournier, 1978b: 96), es decir, que no se puede escapar de aquello que está en los orígenes de cada uno, no se puede enterrar un componente de la dualidad y olvidarlo en beneficio de su opuesto porque el ser humano es dualidad. Como una severa lección de humildad, la aceptación de la propia condición se ha llevado a cabo gracias a esa criaturaespejo que es el payaso:

Ce qui confère à la figure du clown sa supériorité fantasque sur les empereurs et les juges, c'est qu'au rebours des puissants qui sont pris au piège de leur parure et des attributs externes d'une vaine tyrannie, le clown est un roi de dérision; portant le vêtement de la parade, il est plus près de se connaître dérisoire et de reprendre humblement possession de sa vérité indigente. À nous de nous apercevoir qu'il nous représente tous, que nous sommes tous des pitres, et que toute notre dignité (puisqu'il est permis ici de paraphraser Pascal) consiste dans l'aveu de notre pitrerie (Starobinski, 2013: 86-87).

Sin caer en los excesos del jansenismo, el relato de Tournier actúa como doble recordatorio -a su amigo y a sí mismo: en esa lista presidida por emperadores y jueces que imagina Starobinski, el artista "serio", presa de su talento y de su gloria, vendría a ser el tercero en discordia. Antes de la consagración final de Raphaël como Augusto aparecen en el texto dos espacios que podríamos denominar de puesta en escena, por ser aquellos donde se desarrolla la actividad artística, remunerada o no, del protagonista. Se trata de espacios morfológicamente opuestos pero que revisten características similares. Ciertamente, la sobriedad de las aristocráticas "soirées mondaines" donde las señoras admiran - "se pâmaient d'attendrissement" (Tournier, 1978b: 87) - al niño prodigio contrasta con el ruido, la agresividad y la oscuridad del local nocturno, "ce local sombre et mal aéré" (Tournier, 1978b: 89) donde se escuchan los "hurlements joyeux de la foule" y el 
"rugissement triomphal dans lequel s'épanouissent la haine, la lâcheté, la bêtise" (Tournier, 1978b: 90-91), lugar donde los burgueses se transforman en "la pègre la plus crapuleuse" (Tournier, 1978b: 91). El espacio inicial está impregnado de simbolismo diurno/ascensional por la presencia de la figura del niño prodigio sentado sobre el taburete que lo eleva, de un cromatismo que remite a las representaciones angelicales ("Blond, bleu, pâle, aristocratique, il était tout à fait Raphaël"), la aparición del arcángel y la música: "Monter vers le ciel comme un chant d'amour mystique les notes du coral" (Tournier, 1978b: 87). Por el contrario, las características del espacio de la sala de fiestas, que serán amplificadas cuando aparezca por segunda vez y transmitidas al circo, son propias del régimen nocturno/descensional: oscuridad, crueldad, agresividad y presencia del Diablo "Le sadisme, la méchanceté et le goût de l'abjection [...] Raphaël reconnut [...] le rire même du Diable" (Tournier, 1978b: 90-91)-, director de un coro infernal -"la houle des rires" (Tournier, 1978b: 95)-, ante el que nada puede hacer el artista con su instrumento descompuesto. Toda idea de orden o armonía desaparece, puesto que "Chaque touche effleurée déclenchait un piège ou une catastrophe, jet d'eau, crachement de fumée, bruit grotesque, pet, rot, pinette" (Tournier, 1978b: 97).

Sin embargo, el proceso de degradación que supone el paso de un espacio a otro no se produce de forma casual, sino que deriva de una característica común a ambos: se trata de lugares concebidos para el espectáculo, para la contemplación. Resulta llamativo que apenas se ofrezcan elementos que permitan calificar físicamente dichos espacios. Ello se debe a que estarán caracterizados por su función, y no por su forma. Es decir, por la posición del público con respecto al artista, del observador con respecto al observado y viceversa. Porque lo que se desarrolla tanto en la "soirée mondaine" como en la sala de fiestas o en el circo es una dialéctica entre sujeto y objeto. De hecho, dependiendo de la posición que se ocupe dentro de esos espacios, éstos recibirán un valor u otro. Esto es especialmente palpable en los casos de la sala de fiestas y el circo, asociados con la diversión, la risa y la felicidad. Son espacios que se definen por una función: el público va al concierto de la "soirée mondaine" a deleitarse del mismo modo que acude a la sala de fiestas y al circo a reír, a burlarse de lo que ve sobre el escenario. La vivencia positiva de los espacios descensionales sólo es posible en un primer momento para el público que mira y ríe con crueldad (sujeto que observa desde la distancia). Para Raphaël, objeto de las miradas y las risas, el escenario será inicialmente poco menos que un potro de tortura.

Incluso en su forma de penetrar tanto en la "soirée mondaine" como en los espacios descensionales el personaje es inicialmente objeto, y no sujeto, pasivo y no activo. En el primer caso son sus padres quienes lo sitúan sobre el taburete para ser admirado por el público, es decir quienes lo obligan a seguir la carrera musical: "On le mit au piano dès qu'il fut en âge de tenir assis sur un tabouret [...] les 
organisateurs de soirées mondaines se le disputaient [...] on l'astreignait" (Tournier, 1978b: 87-88) ${ }^{4}$. Por otro lado, su descenso a los infiernos no se produce por voluntad propia, sino obligado por la presión económica y los argumentos de su mujer.

Este posicionamiento objeto/sujeto articula la relación del personaje de Raphaël Bidoche con los espacios que ocupa y es la expresión de su evolución interna. De hecho, esa relación marca la caracterización del espacio de la sala de fiestas y el circo, que no es infernal en sí (recordemos que antes de penetrar en él se lo caracteriza de forma bastante neutra y objetiva como un "local sombre et mal aéré"). No será hasta después de un nuevo segmento descriptivo -"Dès le premier soir [...] la bêtise" (Tournier, 1978b: 90)-, es decir de la primera experiencia de dicho espacio por parte del personaje, cuando adquiera características infernales: "le rire même du Diable [...] son enfer quotidien" (Tournier, 1978b: 91). Por lo tanto la espacialidad del relato deriva de la vivencia del espacio por parte del personaje principal, y no del espacio en sí.

En la escena inicial, ese niño-objeto puesto en el taburete por sus padres y observado por el público consigue revertir la situación y convertirse en sujeto: con su acción actúa sobre los espectadores, que pasan a ser objetos, presas del encantamiento producido por el talento del músico ("pâmaient d'attendrissement"). Es decir que los que miraban, ahora son los que reciben los estímulos y permanecen dominados por los mismos. Esta inversión también es capaz de llevarla a cabo el payaso Bodruche, puesto que convierte mediante sus actos conscientemente ejecutados (a diferencia de la comicidad involuntaria de Bidoche) a unos "braves bourgeois" en "la pègre la plus crapuleuse" (Tournier, 1978b: 91). No cabe duda que lo que diferencia a Bodruche de Bidoche es que el primero se encuentra en el escenario de la sala de fiestas en su medio natural, puesto que es un payaso y tiene conciencia de serlo, mientras que Bidoche se encuentra desplazado, despojado de su identidad.

A lo largo de la paulatina bajada a los infiernos que supone su trayectoria como artista de sala de fiestas y circo, se nos muestra a un Raphaël Bidoche torpe, que no sabe cómo actuar, aplastado por la acción del público, "cinglé par les flashes des photographes, les gestes désajustés par la panique" (Tournier, 1978b: 94). Su incapacidad para mantener el equilibrio sobre el taburete que se desmonta -"Le malheur voulut que son tabouret fût trop bas [...] malheur supplémentaire de faire tomber ses lunettes sans lesquelles il ne voyait rien" (Tournier, 1978b: 95)contrasta con su actitud de encumbramiento sobre el taburete al principio. Resulta simbólica la presencia del taburete en estas dos escenas, puesto que mediante la comparación de ambas podemos observar los valores opuestos e invertidos de dicho

\footnotetext{
${ }^{4}$ Los verbos subrayados marcan el carácter pasivo del niño.
} 
objeto: en la primera el taburete lo eleva hacia lo sublime, en la otra lo arroja hacia lo abyecto.

En el mundo infernal, Raphaël Bidoche es objeto. Ni siquiera es capaz de decidir sobre su propio destino, puesto que sus palabras hacia su jefe se ven transformadas, manipuladas por las características del espacio que transita: "Raphaël était entré dans le bureau pour protester. Il en ressortit en remerciant le directeur, et en maudissant intérieurement sa timidité, sa faiblesse" (Tournier, 1978b: 92). En cambio, en la escena final, al recuperar el control del piano, recupera su papel de sujeto ante el que los espectadores guardan silencio y entran en comunión, guiados por el sonido que produce y la aparición del ángel. La dirección del flujo se revierte, puesto que ya no son los espectadores los que actúan sobre el artista, sino al revés. Mediante este mecanismo, el espacio infernal deriva en otro de carácter celestial (ascensional), el objeto paciente y sufriente se convierte en sujeto y se eleva, mismo procedimiento al que habíamos asistido en la escena inicial.

En un primer momento, Raphaël Bidoche está sometido a las leyes del espacio que ocupa, pero mediante su paso de objeto a sujeto consigue apropiarse del mismo y hacer del circo una sala de conciertos. En la escena final se produce una ruptura de la dualidad espacial a todos los niveles: sala de conciertos/circo, ascensional/descensional, sublime/abyecto, producto de la ruptura de la dualidad interna de Raphaël Bidoche. El estado de felicidad con connotaciones trascendentes ("joie") o sublimación corresponde a la asimilación de dos extremos opuestos, ambos parte integrante de la identidad del personaje.

La cuestión de la mirada, de enorme importancia en la obra de Tournier, está relacionada con la diferencia que el autor establece entre los conceptos de imagen y semejanza. A partir de la fórmula del Génesis (1:26) "Y dijo Dios: Hagamos al hombre a nuestra imagen, conforme a nuestra semejanza", Michel Tournier define el primer concepto como "un masque superficiel" y afirma que la semejanza "comprend tout l'être -corps et âme" (Tournier, 1982: 47). Como vemos, la semejanza engloba a todo el ser, y no únicamente su apariencia.

Por otro lado, el hecho de que el cuento presente el proceso de madurez de Raphaël Bidoche desde su infancia hasta la edad adulta nos remite a otro tema recurrente en la obra de Michel Tournier que también está estrechamente vinculado al tema de la duplicidad y al motivo de la mirada. El niño, encarnación de la mirada pura, de la comunión con el mundo y de la unidad del yo, sufre un proceso de ruptura en la pubertad que precipita su caída en la historia y la inversión de los valores del mundo que le rodea (el instrumento, la casa, el arte...). Dicho proceso viene marcado por la presencia de una figura alegórica mediadora entre dos etapas de la vida: el hada Pubertad. No nos entretendremos en explicar las similitudes de la "ruptura" sufrida por el niño con el esquema bíblico ya comentado, pero sí haremos referencia a una característica común a ambos que implica una confrontación visual con el otro.

Antes del pecado original, señala Fui Lee Luk, el hombre y la mujer iban desnudos y se mostraban despreocupados -quizá inconscientes- ante la mirada ajena. Sin embargo, "en mangeant le fruit de la connaissance du bien et du mal, les 
deux premiers humains ont condamné leur descendance à la conscience et à la peur du regard d'autrui" (Luk, 2003: 10). En "Que ma joie demeure", cada uno de los tres momentos en que el personaje, a lo largo de ese proceso de madurez, se muestra a ojos del público, corresponde a una etapa del esquema teleológico judeocristiano: paraíso (soirée musicale), caída (espectáculo en la sala de fiestas) y redención (consagración final de Raphael como Augusto).

El estado de conciliación de los opuestos al que llega Raphaël Bidoche en su madurez sería, en cierto sentido, una recuperación por parte del adulto de la mirada del niño, sin dejar por ello de ser adulto. O lo que es lo mismo: una aprehensión de ambas miradas en una sola. Afirma Arlette Bouloumié:

La conception que Michel Tournier se fait de l'écriture est initiatique. C'est par elle qu'il espère retrouver l'enfant qu'il a été, remonter aux origines, au monde primitif de l'Age d'Or. Son œuvre lui permet de restaurer l'objet perdu. L'écrivain est ainsi le médiateur idéal entre l'enfant et l'adulte en quête du paradis de l'enfance car il garde une âme d'enfant en bénéficiant du génie éminemment adulte de la langue (Bouloumié, 1988: 231).

En realidad, el motivo de la mirada está presente desde la dedicatoria del cuento, puesto que en ella confluyen tres instancias: un remitente, un destinatario y un testigo: el lector. Tournier no concibe en ningún caso el texto como un mensaje íntimo dirigido exclusivamente a su amigo - de ser así hubiera empleado la segunda persona "te". Por el contrario, incluye en él al lector, evidentemente como destinatario potencial (de no ser así no habría publicado el relato), pero también como testigo de ese encuentro entre el escritor y el cómico. La dedicatoria constituye así una puesta en escena del yo tournieriano, expuesto deliberadamente a la mirada del público antes de ponerse la máscara de la ficción. En palabras de Fui Lee Luk: "La ressemblance d'une image et d'un modèle est donc une affaire subjective qui dépend du regard du spectateur" (Luk, 2003: 52).

Esa mirada del otro es en la obra de Tournier constructora de la identidad del yo, como ya demostró Gilles Deleuze en su ensayo sobre Vendredi ou les limbes du Pacifique: "Ce n'est pas le moi, c'est autrui comme structure qui rend la perception possible" (Deleuze, 1969: 267). Así, el texto de "Que ma joie demeure" supone una representación de esa otredad tanto a nivel estructural como a nivel temático, puesto que parte de un desgarro inicial y culmina con una conciliación final: de los dos polos del yo por una parte, y de realidad y mundos de referencia por otra.

Como en la definición de escritor que analizamos en la introducción, la presencia del otro o de los otros (el destinatario de la dedicatoria, el narrador, el lector) cumple una función creadora de identidad al establecer una relación dialéctica con el yo. Y no lo hace a modo de espejo, sino de espejo y de máscara a un tiempo. El dispositivo ficcional, inversión positiva de la experiencia no vivida, formará pues parte de la identidad del autor, como concluye Luk en su comentario a la interpretación paradójica que hace Tournier de la teoría de Barthes:

Tournier se distingue de Barthes sur un point: alors que celui-ci conteste l'idée que quelqu'un "nourri[sse] le livre, c'est-à-dire qu'il existe avant lui, pense, souffre, vi[ve] pour lui", selon un rapport père/enfant, l'auteur de Vendredi est plus partagé. En fait, la conception tourniérienne du 
rapport auteur/œuvre est plutôt contradictoire. Tout en soutenant à plusieurs reprises que l'auteur n'est que le "sous-produit" de l'œuvre [...], le romancier ne nie pas la responsabilité paternelle qu'il ressent envers celle-ci; selon lui, l'écrivain est contraint de suivre les exigences du manuscrit (Luk, 2003: 114).

\section{Esto es:}

Tant qu'un personnage gagne en couleur et en complexité, il échappe au contrôle du créateur, obligé de le suivre dans un voyage imaginaire plein de péripéties imprévues, il enrichit l'auteur de nouvelles connaissances, il transforme l'être de l'autre qu'il possède comme un "démon". Tournier adopte souvent la voix de ses personnages, stratégie qui sert à installer une distance entre lui et son public. [...] Asservi à l'œuvre qui dévore sa substance au point qu'il ne reste plus rien de luimême, l'écrivain intègre les créations de son imagination à sa propre réalité (Luk, 2003: 115).

De ahí que el hecho de que los escritores sólo existan en sus libros le parezca a Tournier "amargo" y a la vez "exaltador": si sólo existen en sus libros, él habría vivido a Grock. Sin embargo, no debemos en ningún modo ver a Tournier como un mitómano que se complace en creerse sus propias invenciones. La confluencia de los dos adjetivos permite, por el contrario, dibujar a un Tournier con una actitud distanciada con respecto a esa exaltación que produce la invención y que amenaza con hacer perder el sentido de la realidad. Antes que "exaltador" es "amargo". Dicho de otro modo: el autor no pierde de vista que toda inversión biográfica, por muy exaltadora que sea, no es sino un artificio literario.

Si Luk recurre el término "tatuaje" para referirse a las diferentes marcas de la presencia del autor de "Que ma joie demeure" en sus textos, debemos añadir que Tournier utiliza el maquillaje y el disfraz constantemente -instrumentos de trabajo del payaso- para darle un sentido (una polaridad si se prefiere) al mundo. $\mathrm{O}$ lo que es lo mismo, para ficcionalizarlo. Esto provoca una distorsión de las fronteras entre realidad y ficción, puesto que una identidad extra-textual se apropia del texto al mismo tiempo que el autor se ve disociado de su identidad real por su entrada en el mundo ficcional (Luk, 2003: 104).

Esta práctica ficcionalizadora de la propia vida, "moyen d'évasion et instrument d'hyperconnaissance" (Tournier, 1977: 48) aparece reflejada en el cuento que sigue a "Que ma joie demeure" en Le Coq de bruyère: "Le Nain rouge", protagonizado por un enano que llega a confundir su identidad civil con la del personaje que encarna en un dueto cómico. Mediante la identidad creada, el protagonista exacerba su potencia física y sexual. Tournier reconoce haberse inspirado para la elaboración de dicho relato en Les mots de Sartre, autobiografía que insiste particularmente en el papel de lo libresco y lo ficcional en la construcción del yo (Tournier, 1977: 184186). La relación intertextual no termina ahí, si tenemos en cuenta la importancia que le da el filósofo existencialista a la mirada del otro en toda su obra.

Mediante el ejercicio de su talento musical, que no es creativo, sino interpretativo, Raphaël consigue transformar el espacio y volver al tiempo mítico de la unidad primordial sólo de manera provisional. Por el contrario, al asumir el papel de payaso, se convierte al mismo tiempo en intérprete y creador, actor y autor. Esto le abre las puertas de la elevación final, cuyas consecuencias identitarias ya hemos 
analizado. Resulta evidente el paralelismo con el escritor que se introduce en sus propios textos como creador y actor, y que al tiempo que concibe la ficción como vivencia experimenta lo creado.

Por lo tanto, una vez finalizado nuestro recorrido por "Que ma joie demeure", creemos poder afirmar que este cuento de navidad merece un lugar destacado en el espacio autobiográfico de Michel Tournier. Espacio que por otra parte es prácticamente infinito, puesto que incluye textos ficcionales, no-ficcionales e incluso obras de crítica literaria. Hablar de los otros, hablar a los otros, hablar a través de los otros es siempre para Tournier hablar de uno mismo, construir una identidad propia y en constante movimiento, según la dialéctica de la cascada expuesta por Jung. Llegados a este punto, nos vemos obligados a matizar la rigidez de las fronteras que el esquema genettiano sitúa entre las distintas instancias narrativas de la ficción heterodiegética: $\mathrm{A}(\neq) \mathrm{N}(\neq) \mathrm{P}[(\neq) \mathrm{A}]$.

Como para muchos escritores y artistas desde el romanticismo, la elección de la imagen del payaso no es para el autor de Vendredi ou les limbes du Pacifique "seulement le choix d'un motif pictural ou poétique, mais une façon détournée et parodique de poser la question de l'art" (Starobinski, 2013: 8). En la definición de escritor que ofrecíamos al principio, el autor se nos presenta con el rostro cubierto por una máscara que nos guiña un ojo mientras contempla en un espejo su propio reflejo grotesco. No se nos ocurre mejor representación del "second degré" propio del payaso blanco en el marco del esquema planteado en Le miroir des idées. Dicho planteamiento no retoma únicamente una estética del espectáculo, sino una poética de la autobiografía en la que Michel Tournier identifica a Rousseau con el payaso rojo, aquél que exhibe ante el mundo su sinceridad y su desdicha, exponiéndose así a la admiración, a la piedad y al desprecio. Evidentemente, se reserva para sí mismo el papel del payaso blanco, aquél que prefiere permanecer a cierta distancia para observar sin exponerse y poder así salir victorioso del lance sin poner en juego su libertad, sus bienes o su persona. Una actitud irónica y distanciada que conserva incluso para describir su propia tumba en la paródica "Nécrologie d'un écrivain. Michel Tournier (1924-2000)": "un tombeau sculpté représentant un gisant au visage masqué par un livre ouvert, porté par six écoliers" (Tournier, 1986: 244$245)^{5}$. A día de hoy, única muerte de Tournier de la que podemos dar fe.

\section{REFERENCIAS BIBLIOGRÁFICAS}

Adam, J.-M., (1990) Éléments de linguistique textuelle. Théorie et pratique de l'analyse textuelle. Bruxelles, Mardaga.

Adam, J.-M., (2005) La linguistique textuelle. Introduction à l'analyse textuelle des discours. Paris, Armand Colin.

\footnotetext{
${ }^{5}$ Cabe destacar la presencia significativa de los niños tanto en su definición de escritor como en su necrológica ficticia.
} 
Albaladejo, T., (1991) Retórica. Madrid, Síntesis.

Barthes, R., (1984) "La Mort de l'auteur" in Essais critiques IV: Le Bruissement de la langue. Paris, Seuil, coll. Points, pp. 61-67.

Benjamin, W., (2000) "Le conteur" in Oeuvres III. Paris, Gallimard, coll. Folio essais, pp. 114- 151.

Bouloumié, A., (1988) Michel Tournier. Le roman mythologique. Paris, José Corti.

Deleuze, G., (1969) "Michel Tournier et le monde sans autrui" in Tournier, M., Vendredi ou les limbes du Pacifique. Paris, Gallimard, coll. Folio, pp. 257-283.

Doubrovsky, S., (1988) Autobiographiques. De Corneille à Sartre. Paris, PUF, coll. Perspectives Critiques.

Genette, G., (1987) Seuils. Paris, Seuil, coll. Points.

Genette, G., (2004) Fiction et diction. Paris, Seuil, coll. Points.

Jung, C. G., (1972) "On the psychology of the trickster figure" in Radin, P., The Trickster. A Study in American Indian Mythology. New York, Schocken Books, pp. 195-211.

Kibédi Varga, A., (1970) Rhétorique et littérature. Etudes de structures classiques. Paris, Klincksieck.

Lejeune, Ph., (1991) "Nouveau roman et retour à l'autobiographie" in Contat, M. (ed.), L'Auteur et le manuscrit. Paris, P.U.F., pp. 51-70.

Luk, F. L., (2003) Michel Tournier et le détournement de l'autobiographie. Dijon, Éditions Universitaires de Dijon.

Starobinski, J., (2013) Portrait de l'artiste en saltimbanque. Paris, Gallimard, coll. Art et Artistes.

Tournier, M., (1977) Le vent Paraclet. Paris, Gallimard, coll. Folio.

Tournier, M., (1978a) "Le Sacre de l'enfant" in Le Monde, 7 de abril, p. 21.

Tournier, M., (1978b) "Que ma joie demeure" in Le Coq de bruyère. Paris, Gallimard, coll. Folio, pp. 85-99.

Tournier, M., (1982) Gaspard, Melchior et Balthazar. Paris, Gallimard, coll. Folio. Tournier, M., (1986) "Nécrologie d'un écrivain. Michel Tournier (1924-2000)" in Petites proses. Paris, Gallimard, coll. Folio, pp. 244-245.

Tournier, M., (1988) "Que permanezca mi alegría" in El urogallo, trad. de Lourdes Ortiz. Madrid, Alfaguara, pp. 91-105.

Tournier, M., (1994a) Le pied de la lettre. Trois cents mots propres. Paris, Mercure de France.

Tournier, M., (1994b) "L'Auguste et le clown blanc" in Le miroir des idées. Paris, Gallimard, coll. Folio, pp. 68-70. 